\title{
A Positive Reflux-Symptom Association Is Not Marked When the Onset of the Reflux Episode Does Not Occur Within the Pre-symptom Time Window
}

TO THE EDITOR: Combined esophageal $\mathrm{pH}$ monitoring and multichannel intraluminal impedance ( $\mathrm{pH}-\mathrm{MII})$ permits the analyses of bolus exposure during volume clearance and acid neutralization during chemical clearance. $\mathrm{pH}-\mathrm{MII}$ has become particularly important for detection and assessment of weakly acidic and/or weakly alkaline (non-acidic) gastroesophageal reflux (GER) episodes in formula-fed infants and patients (in general) taking stomach acid reducing medications. The technology has been widely regarded for its ability to test the association of symptoms with GER, regardless of the acid content. By convention, a GER event occurring within the pre-symptom time window (eg, 2 minutes) is considered to be temporally associated with the symptom. ${ }^{1}$ Hence, symptom association indices (SAI) (the symptom index, the symptom sensitivity index, and symptom association probability index) can be calculated as an objective quantification of the temporal relationship between GER and symptoms. ${ }^{2-5}$ SAIs are calculated by the system software and rarely by the system operator (technician or clinician). A positive (or negative) SAI can have a major impact on the decision-making process as the clinician develops a strategy for clinical management of the patient.

Combined $\mathrm{pH}$-MII for assessment of GER symptoms in infants and children has been used at our institution since the early 2000s. Consequently, some important observations regarding the manner in which $\mathrm{pH}$-impedance system software establishes temporal relationships and calculates SAIs have been made. One important observation is reported with regard to the Medical Measurement Systems pH-MII system (Netherlands), in particular. For symptom-GER association, if the "onset" of the GER event occurs within a selected time window (we use 120s), the software marks a positive symptom-GER correlation. Otherwise, it marks a negative correlation. Acid GER (AGER) episodes that overlap the pre-symptom time window but are not initiated within the window will not be temporally associated with the symptom. Figure shows a bi-phasic AGER episode during which the majority of volume clearance and all of chemical clearance overlaps with a 2-minute window. While likely associated with the symptom (in this case, abdominal pain), this AGER episode is not registered by either the $\mathrm{pH}$ probe or the impedance catheter as a positive association because neither metric onsets, $\mathrm{pH}$ and impedance (2:28:31), are initiated within the pre-symptom time window (2:28:37-2:30:37).

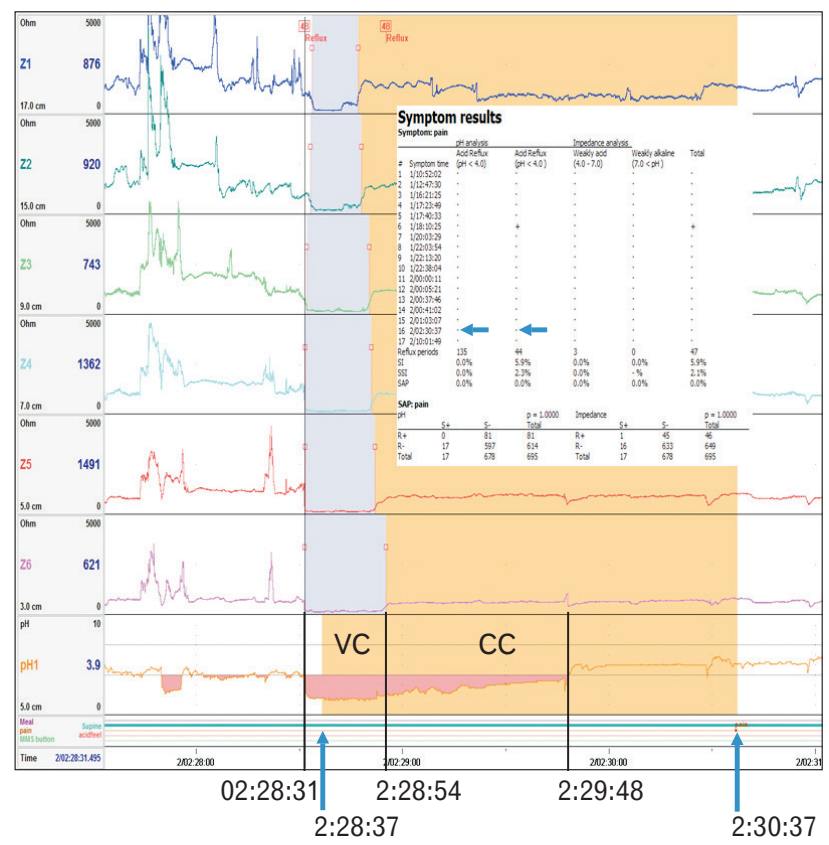

Figure. Acid gastroesophageal reflux (GER) overlapping a presymptom time window. The figure demonstrates that GER episodes, whether measured using a $\mathrm{pH}$ probe or impedance, will not be temporally correlated with a symptom if the onset of the GER episode does not take place within the pre-symptom window. $\mathrm{VC}$, volume clearance; $\mathrm{CC}$, chemical clearance. 
The possible clinical significance within patients with varying GER-response thresholds has the potential for concern. Failure to recognize and include one or more symptom-GER associations could prevent an accurate diagnosis. This characteristic of the system algorithm must be considered when analyzing and editing the pH-MII tracing. The study diary can be edited to re-mark the symptom onset at an earlier time point so that this association can be captured and considered for SAI calculations.

Frederick W Woodley ${ }^{1,2,3}$ ${ }^{1}$ Motility Center, Nationwide Children's Hospital, Columbus, Ohio, USA; ${ }^{2}$ Division of Gastroenterology, Hepatology and Nutrition, Nationwide Children's Hospital, Columbus, Ohio, USA; and ${ }^{3}$ Department of Pediatrics, The Ohio State University College of Medicine, Columbus, Ohio, USA

1. Weusten BL, Roelofs JM, Akkermans LM, van Berge-Henegouwen GP, Smout AJ. The symptom-association probability: an improved method for symptom analysis of 24-hour esophageal pH data. Gastroen- terology 1994;107:1741-1745.

2. Wiener GJ, Richter JE, Cooper JB, Wu WC, Castell DO. The symptom index: a clinically important parameter of ambulatory 24-hour esophageal pH monitoring. Am J Gastroenterol 1988;83:358-361.

3. Breumelhof R, Smout AJ. The symptom sensitivity index: a valuable additional parameter in 24-hour esophageal $\mathrm{pH}$ recording. Am J Gastroenterol 1991;86:160-164.

4. Ghillebert G, Janssens J, Vantrappen G, Nevens F, Piessens J. Ambulatory 24-hour intraoesophageal $\mathrm{pH}$ and pressure recordings $\mathrm{v}$ provocation tests in the diagnosis of chest pain of oesophageal origin. Gut 1990;31:738-744.

5. Armstrong D, Emde C, Inauen W, Blum AL. Diagnostic assessment of gastroesophageal reflux disease what is possible vs what is practical? Hepatogastroenterology 1992;39(suppl 1):3-13

Financial support: None.

Conflicts of interest: None. 